of a long narrow knife (Fig. 1), with its cutting edge turned upwards, is then to be entered in the sclerotic (at the point A, Fig. 2, which represents the left cornea), near the upper and outer portion of the comea, about one-third of a line from its edge, so that it may enter the anterior chamber quite at the periphery. The point of the knife should be at first directed downwards and inwards, towards $c$, the edge of the blade being turned a little forwards; and then,

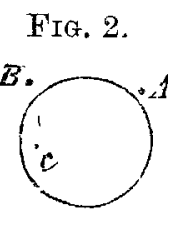
when the blade has advanced about three and a half lines into the chamber, the handle is to be depressed, and the point carried along to $\mathrm{B}$, where the counter-puncture is to be made, at a point exactly corresponding to the puncture $A$. As soon as the counter-puncture has been made, the edge of the blade is to be turned somewhat obliquely upwards and forwards, and the knife pushed straight on until its length is nearly exhausted, when the section is to be completed by drawing it backwards from heel to point. The knife will then lie under the conjunctiva, which is next to be divided, in such a manner as to leave a conjunctival flap of about one to one and a half lines in height.

2. The iridectomy.-The little conjunctival frap should be turned back over the cornea with a very small pair of iris forceps, which will las bare the prolapsed portion of iris ; the latter should, if necessary, be drawn out a little further, and excised to the required extent, quite close to the ciliary insertion. This is not, however, to be done by one cut, but by three or four successive snips with the scissors, the blades of which are to be slightly turned, so as to follow the curvature of the eyeball. Great care should be taken to snip off the iris quite close to the section, especially at the angles of the latter, where little protrusions of iris are apt to occur.

3. Laceration of the capsule. - The operator, steadily fixing the eyeball with the forceps, next proceeds to lacerate the capsule freely with the pricker by successive incisions. The one is to commence at the lower edge of the pupil, or even a little behind it beneath the iris, and extend upwards along its inner side; the other passing to the same extent along the outer margin of the pupil. Both incisions should reach quite up to the periphery of the lens exposed by the iridectomy. Finally, the capsule should be lacerated at its periphery in a line corresponding to the section. In using the pricker, its edge should always be turned in a slanting direction, and not be pressed firmly backwards, otherwise the cataract may be dislocated into the vitreous humour, or its upper margin displaced behind the upper edge of the incision.

4. Removal of the lens.-The eye being fixed by the forceps, which are to be applied a little below and on one side of the centre of the lower margin of the cornea, the back of the silver curette (or Von Graefe's vulcanite curette) is to be placed upon the lower margin of the cornea, and pressed slightly backwards and upwards, so as to cause the upper edge of the lens to present itself in the section; and then the pressure is to be made directly backwards, in order that the lens may be rotated round its transverse axis, and tilted well forwards into the wound. When this has occurred, its exit is to be gently aided by pushing the curette slowly upwards over the surface of the cornea, so that it follows step by step the delivery of the lens. If it is found that portions of the lower cortical substance are stripped off and ale inclined to $\operatorname{lag}$ behind, the curette should be drawn back again a little, and the fragments of cortex pushed along after the body of the lens, and in this way the whole of the cataract will generally be removed. If the appearance of the cataract indicates the presence of a good deal of soft matter, it is well to work this gently towards the centre by pressing the curette lightly from the lower and lateral margins of the cornea towards its centre, before attempting to remove the lens, for thus we may generally succeed in getting the soft matter to exude with the firmer nuclear portions. If small fragments of lens-matter still linger behind after the body of the cataract has been removed, they should be coaxed out by again passing the curette over the cornea, and pushing them on in front of the instrument; $o x$, as Von Graefe advises, the lid-holder having been removed, the operator should gently rub the lids, more especially the lower one, in a circular direction, and thus loosen the marginal portions of cortex from behind the iris, and bring them into the area of the pupil, and thence out through the wound.

\section{ON THE EARLY DETECTION OF INFECTIOUS DISEASES.}

Bx ROBERT FARQUHARSON, M.D. EDIN. MEDTCAL OTFICER TO REGBY SCHOOL, LATE ASSIST.-SLRGEOY COLDSTREAM GEARDS.

I AM induced to offer a few remarks on this subject, not because my opportunities for its investigation have been greater than those of others, but because circumstances have convinced me of its paramount importance. The position of medical officer to a large school, among its many responsibilities, involves none greater or more pressing than the necessity of limiting infectious disease by its early detection and removal. To discriminate between trifling complaints and those of a more serious character is at all times desirable, but especially so when the slightest error of judgment may encourage the spread of contagion through a large number of boys. And yet it is peculiarly requisite to observe due cantion in such decisions, avoiding rashness and hasty judgment above all things, as the effect of any panic on so susceptible a community can hardly fail to produce evil effects.

Now there is no difficulty in recognising a case of measles or scarlet fever when the symptoms are well pronounced; when the skin, and the throat, and the eyes, and the tongue tell their plain story. But to distinguish these from other affections before their specific phenomena are developed is a task which not only tries the skill of the most accomplished observer, but is confessedly so hard that it is frequently nerer attempted at all. How often do we evade the necessity of such a decision, on the ground that at so early a period diagnosis is impossible, and that time alone will show what the result is to be:-as though febrile and eruptive diseases were originally cast in some uniform mould of formative material, from which chance constructs this or that form. Such a method of eluding responsibility gratifies the natural indolence of our nature, and saves our selfesteem from the unsatisfactory possibility of a false prediction; but it lags sadly behind the requirements of this advancing age. It is, perhaps, not unnatural that the value of premonitory symptoms stands in danger of being over looked amid the more brilliant and exciting investigations of modern medicine, but the labours of sanitarians show us more plainly day by day how requisite it is to have clear notions on this subject; and it is not too much to expect that, before long, coming events may cast not only their shadows but their outlines before, and enable us to state with absolute fidelity whether any group of phenomena in. dicates serious disease or superficial derangement. The more we are thrown among men of learning and accurate habits of thought, the more formed will be the opinions expected from us on these points, and the greater will be our embarrassment if we fail. For, to the student of the exact sciences, the comparative want of precision in our present system seems almost incomprehensible; and hence it is that the facile theories and gratuitous assumptions of homœopathy find ready belief.

Now, when the young practitioner has got over the feelings of diffidence naturally resulting from the loss of leadingstrings, his transition from the public to the private bedside would be easy enough, were it not for this difficulty. And yet he brings to his task no mean accomplishments: he is well versed in the theory of his art; and he has enjoyed the privilege of witnessing a greater or smaller number of various maladies in varying forms of intensity. But these are necessarily advanced and established cases; and, from unavoidable causes, the hospital wards have not furnished him with the opportunity of observing the early and insidious approach of illness, or of acquiring materials for the elucidation of the many and intricate questions which are certain to arise during his professional career. Nor when he takes his turn at out-door work are his facilities notably increased; for although our poorer classes are nervous and much given to false alarms, it is seldom that they have either leisure or observation sufficient to detect the first gradual onset of sickness. Private practice is therefore the only efficient school for this class of knowledge; and when 
called by an anxious parent to give a decided opinion as to the signification of certain symptoms, his hesitating demeanour may too surely prove the disadvantage of having to learn as he goes along; and by the time his lesson is acquired, the confidence not only of his patients, but, what is worse, of himself in his own powers, can hardly fail to be seriously shaken. The tact, on the other hand, which he acquires by a long course of experience is not always of a kind to be readily communicated to others. It is usually something personal, engrained, as it were, in his nature; and it will of ten be found that he jumps to a conclusion by a sort of intuitive perception, indefinable even to himself. Hence it is that so large a mass of this sort of capital is floating about, - of great service to its possessors, but not bearing the interest it might do were it laid out and lent to the world at large; and in venturing to say a few words on the detection of some of our commonest diseases, I only do so in the hope that I may induce others, with more matured judgment and wider fields of observation, to take up the subject with better prospect of success.

I shall begin with scarlet fever, which has recently excited so much attention by its unusual prevalence. I believe that by early removal we can always most effectually stamp out an epidemic of this disease; and within the last few months I have had a satisfactory opportunity of putting this to the test. Three distinct cases appeared in three detached boarding houses, each containing over fifty boys. They were at once conveyed to the School Hospital, all the bedding in their dormitories was changed, and a free current of air permitted to pass through the rooms. The beds were occupied again as usual at night; and in only one case was this outbreak followed by a second instance of infection. The attack is usually sudden, frequently ushered in by vomiting, headache, and aching of the limbs; but in my experience sore-throat is the earliest symptom complained of. In one case a boy, while at tea, felt all at once as though a piece of bread had stuck in his throat. Next morning he grew sick and faint, and the eruption appeared. Some feel sore and chilly, and consider that they have taken cold; and one lad experienced so much pain and stiffness in his legs that he had some difficulty in going up stairs. This quite coincides with my own recollection of such an attack many years ago, when excessive aching of the limbs and sore-throat first attracted my attention. The tongue is large, flabby, and moderately furred, but does not assume its characteristic aspect until the beginning of the eruption. The pulse is very quick and sharp, the skin hot and pungent, and after twenty-four hours the eruption appears on the chest in the form of punctated spots, somewhat resembling elevations of the papillæ of the skin. Sudamina, which are regarded by $\mathbf{M}$. Trousseau as giving a pathognomonic character to the scarlatinal rash, I have but rarely observed. The throat is red, the palate covered with granular prominences, and the tonsils are enlarged and studded with whitish flakes, which when once seen leave no doubt as to the nature of the disease. The thermometer is here of no service, as the most doubtful cases are invariably those of acute tonsillitis, in which the temperature is often raised three or four degrees. Putting a patient to bed will frequently develop an undefined eruption in a wonderful manner ; and in children, in whom great heat of skin is produced by trivial causes, a full dose of the solution of acetate of ammonia will often aid our diagnosis. I was some time ago summoned to a little girl who had been ailing for two or three days, and had a slight fit before my visit. I found her dull, heavy, and sleepy, with a quick, sharp pulse (140), hot skin, temperature $103^{\circ}$, slight sore-throat, and furred tongue. I ordered a warm bath, and a diaphoretic dranght; and next day the child walked into the room in perfect health, removing the suspicion of some probable eruptive disease which I had thought it my duty to communicate to the parents.

Doubt may occasionally arise in our minds when called to see nettle-rash in some of its many forms; and when we find that a boy, after some sickness and headache, is invaded by a scarlet eruption composed of punctated spots, and associated with sore-throat and general febrile disturbance, we may feel ourselves somewhat puzzled. But we may generally come to a right decision by observing that the skin by its itching and tingling is evidently the main source of discomfort; that the throat affection is entirely confined to redness and odema; and that the thermometric indica- tions of increased temperature are not sufficient to balance the local phenomena. Such cases are very commonly met with in our large public schools, as a consequence of stomach derangements from too frequent visits to the confectioner and it is very satisfactory to be able to allay the alarm and anticipation of evil which their appearance suggests.

But still greater difficulty will be experienced with some of those cases of acute tonsillitis where rigors, aching in the limbs, rapid pulse, furred tongue, and hot skin seem to point to something serious. The characters of the throat, and the want of sharpness, so to speak, of the fever, may frequently lead us to a correct judgment; but it will now and then happen that the most careful examination will not go further than suggest the propriety of suspending our verdict for twenty-four hours.

I feel somewhat more confidence in approaching the subject of measles, as, some years ago, while serving in the Coldstream Guards, forty-four cases came under my treatment, during a severe and long-continued epidemic. Having: carefully observed and noted their symptoms and progress, I now append an analysis of the conclusions to which I have been led.

This disease is usually gradual in its onset, beginning with languor, want of appetite, listlessness, and debility, which are apt to be considered due to, and treated as, simple gastric derangement. The patient looks dull and heavy, is fretful, and sleeps badly, tossing about restlessly, and wandering from time to time. In four of $\mathrm{my}$ cases violent and most alarming fits occurred, proving fatal in one instance. There is generally a short, sharp cough, and the invariable injection of the conjunctiva and mucous irritation appeared-sometimes early, but more frequently rather late-among the premonitory symptoms. In one case, the sudden occurrence of vomiting, flushing of the face, and headache after dinner, and in another severe sickness, obliging the child to leave school, were the first indications of the coming attack. Sore-throat, rigors, and bleeding at the nose were rare. The tongue was always white, and diarrhœa was present in eight cases, being sufficiently urgent in several to accasion marked depression. Constipation was well marked three times. The eruption in thirty-nine cases in which this point was noted appeared on the fourth day in twenty-eight, once on the ninth, five times on the seventh, and twice on the second; but this evidence seems insufficient to disturb the usual rule, the exceptions not being sufficiently uniform to suggest much beyond a probable exror of observation. It appeared in the form, rarely of broad florid patches, but more commonly as small dull-red papules on the root of the nose and forehead, from thence spreading to the rest of the face and the body. On one occasion it began on the body, and in another made its first appearance behind the ears. When it becomes fully developed diagnosis is of course easy; but difficulty may occasionally be excited by some of the varieties of nettlerash-more especially that depending on the action of copaiba or iodide of potassium, in which, however, the spots are brighter and the febrile oppression less intense. Previous to the establishment of the rash the temperature is seldom raised more than one degree, and the thermometric indications may even mislead, as in the case referred to above, where a child was sent home from school with vomiting, followed by flushing and fever at night. When $I$ saw him next day, the temperature was $97 \cdot 3^{\circ}$, and I expressed a confident opinion that he was merely suffering from gastric derangement. Three days later he was covered with the eruption of measles.

In small-pox we usually meet with persistent headache and flushing of the face, bleeding at the nose, a peculiax dulness and heaviness of aspect, sickness, and pain in the back. On one occasion the head symptoms were so acute as to lead to a suspicion of congestion of the brain, and to the performance of cupping at the back of the neck. The eruption usually appears in the first instance on the left side of the forehead, at its junction with the hairy scalp; and sore-throat, with papules on the mucous membrane, generally follows.

I have seen one case in which the eruption appearing on a syphilitic subject was mistaken for the secondary manifestation of that disease; and several in which, on the other hand, an outbreak of venereal pustules, with their attenclant fever, was diagnosed small-pox.

In chicken-pox, after a period of mild febrile disturbance. 
a fer delicate resicles appear on the face, neck, and occasionally throat. Their presence on the scalp I should consider pathognomonic.

In mumps we meet with slight feverish symptoms, followed by pain on movements of the jaw, depending on the fact that the portion of the parotid in front of the ear is invariably first attacked, and can be felt as a tender swelling. If we attend to this, we may readily dispel the false alarins frequently excited during an epidemic by the acute engorgements of the cervical glands secondary to ulceration of the tonsils; and it is especially necessary to have a clear conception of this affection, as its infectious influence is unusually subtle and persistent, and it has always been one of the great scovrges of our large schools.

I have limited my remarks to the above diseases, not only because they are those with which I have been most larcely brought in contact, but because they are those which demand most careful study from all who have the responsible charge of closely-aggregated masses of youth of either sex. It will frequentiy cccur to them to be expected to give decided opinions from apparently insufficient data; and to feel, as $i$ daily do, the want of rigid rules for their guidance. It may be that, in future years, our powers of dia gnosis may acquire such marvellous refinement as to enable us to detect the first entrance of infection into the system, and to expel it as readily as an emetic frees the stomach from poison, or the knife or cautery oux tissues from the deadly renom of the snake. Where this insidions principle luris during its incubative stage, whether it lies dormant in the blood, the lungs, or the digestive tube, must for ever lemain a secret until we can isolate it essence by our microscope or test-tube. But our best chance of ever arriving at such a point of perfection must consist in carefully tracking the contagious principle to its resting place in this or that part of our frames, and by binding together into one compact mass the scattered threads of clinical experience. For even although failure mar attend our efioris to penetrate so far into the mysteries of truth, consolation will not be far distant, when we consider the ripe harvest to be thus gathered in other and less distant fields.

Rugbs, Fotember, 1869.

\section{ON THE TREATMENT OF CARBUNCLE.}

BY PETER EADH, M.D. LOND., M.R.C.P., BHSICIAN TO THE YORFOLK AND TORWICH HOSPITAL, ETC.

THE following case of carbuncle has recently occurred in my practice; and as recovery took place in spite of its formidable size and the advanced age of the patient, and as the observed effects of the treatment adopted tend to confirm the view as to its intrinsic nature which was expressed by $\mathrm{M}$ r. Startin some three years ago, I have thought it of sufficient value to justify its insertion in TrE Larcer.

On reforring to the descriptions and reputed causes of this disease given by some of our ancient writers, and comparing these with the account given in our more modern treatises on Medicine and Surgery, one cannot help being struck with the small advance which has been made, in the course of these many centuries, in our knowledge of this singular disease. The descriptions of the tumour and the morbid phenomena it presents in its course are, it is true, elaborated and more accurately defined, and more minute descriptions are given of the attendant circumstances and of the treatment recommended; but still the same vagueness of knowledge as to its exact cause, the same evident ignorance as to its intimate nature, are everywhere discernible; and the only real change is, that the "melancholic" or "hot, thick, and black" blood, which, by "fermenting, overheating, and fixing in a part," has caused its inflammation and sloughing, has been exchanged as causative influence for " a scorbutic or putrid state of the fluids" (Benjamin Bell)-“" a vitiated state of the blood" (Tanner) - "inflammation of the true skin, and the deposit therein of unhealthy lymph, usually caused by blood disorder" (Druitt) _- "inflammation of a destructive kind, the purpose [of which] is elimination" (Erasmus Wilson)- "frequently attended with diabetes" (Watson).
Mr. Startin has at last broken fresh ground, and has or appears to have made a distinct advance in our knowledge of its special nature and pathology. In the paper to which I refer," he says: "I reoard these maladies [boils and carbuncles] as having frequently or constanily a parasitic origin, and treat them accordingly. I slould mention that this opinion is rather borne out by the success and effience of the practice in the cure of these ailments than by microscopic verification; though in an example cr two, amongst very many failures, this test has demonstrated croptogamic regetation resembling what is found in sycosis."

Acting upon these views, I not only adopted the treat. ment he has recommended, but I carried it still further, by introducing into every possible portion of the mass a strong solution of carbolic acid, so as to bring it into direct contact with the sloughing tissue.

J. P_, aged seventy-four, a remarirably hale, stout, and robust main of his age, free from other bodily disease, although the subject of chronic mania, was attacked about Sept. 2 sth with carbuncle of the back of the neek. It began, as usual, as a small inflamed and thickened spot, and the central thickenino and circumferential redness oradually increased, with about the usual amount of pain and constitutional irritation. On Sept. $28 t h$, four days after the commencement, being then about three inches in diameter, a free crucial incision was made across it, and then poultices of linseed meal were constantly applied; but it continued steadily to enlarge. Five days later, its progress being still quite unchecked, and its diameter having considerably increased, it wes again freely divided crucially; and next day - the cut portions of the carbuncle, as well as its numerous small openings, having begun to discharge dirty pus and small strings of sloughy tissue-the poultices were omitted, and it was covered all over with lint saturated with oil containing one part to five of carbolic acid, at the same time that strips of lint soaked in the same were laid in the fossæ formed by the division of the diseased mass, and were also freely inserted into all the natural openings which had formed in it, all being renewed at intervals of a few hours. At the end of two days a very remarkable change was observed. All the internal parts of the tumour with which the carbolic acid had come in contact had lost their bluish and dixty-sloughy appearance, and had now a remarkably red and florid look, with fresh granulations rapidly springing up in them; and the tumour had evidently ceased to spread on the right side, which was, in reality, the one where the small openings were most numerous, nearest to which the incisions had been made, and where, consequently, the carbolic oil had been most completely and thoroughly applied. As the left side, however, still continued to extend, and as this spreading appeared to be but little, if at all, checked by the incisions, a deep eschar of two inches' diameter was now (Oct. 6th) made near its outer edge with acid nitrate of mercury, the car'bolic oil applied as before, and the whole covered (as advised by Mr. Startin) with a poultice smeared with mercurial ointment. After this the carbuncle, which had now attained a diameter of several inches, and in fact almost covered the entire surface of the back of the neck, ceased to spread; the circumferential redness subsided; the solid centre passed through its stage of boggy softening quickly, and with a small amount of suppuration; only a few very small pieces of core or slough were discharged; and in a few days the soreness and swelling were nearly gone, the patient was eating voraciously, and was in fact well. He was throughout supported as fully as possible by liquid rood and a large supply of stimulants, but not much medicine was taken. During the course of the treatment several small festers or incipient boils appeared around the margin of the carbuncle, but they were all completely aborted by the free application of the acid caustic to their apices.

In considering this case, two points appear to me to be worthy of notice.

1. The great age of the patient, and the large size of the tumour; in spite of which recovery took place.

2. The influence of the treatment adopted in producing the favourable result.

On the first point I would only say that, though doubtless many aged patients do survive an attack of carbuncle, even when as extensive as this one, yet that the rule is the other way, and that a carbuncle of any great size in an

* British Medical Journal, Nor, 1866. 